\title{
INSPEÇÃO VISUAL E MAPA DE DANOS DE MANIFESTAÇÕES PATOLÓGICAS EM FACHADAS DA IGREJA MATRIZ DE BOA VISTA EM RECIFE-PE
}

\section{VISUAL INSPECTION AND DAMAGE MAP OF PATHOLOGICAL MANIFESTATIONS IN FACADES OF MATRIZ CHURCH OF BOA VISTA IN RECIFE-PE}

\author{
PAULA, HiAgO ALVES DE \\ Estudante de Engenharia Civil \\ Universidade de Pernambuco \\ Pernambuco; Brasil \\ hiago.alves.p@gmail.com
BARRETO, LYDIA MARQUES DE
Arquiteta
Pernambuco; Brasil
lydia_barreto@hotmail.com \\ Universidade de Pernambuco
}

\author{
MONTEIRO, ELIANA CRISTINA BARRETO \\ Engenheira Civil \\ Universidade de Pernambuco \\ Pernambuco; Brasil \\ eliana@poli.br
}

\author{
MOURA JR, JOSÉ MARIA DE \\ Estudante de Engenharia Civil \\ Universidade de Pernambuco \\ Pernambuco; Brasil \\ jmdemjr@gmail.com
}

\author{
NASCIMENTO, THULIO ROBERTO SILVA DO \\ Estudante de Engenharia Civil \\ Universidade de Pernambuco \\ Pernambuco; Brasil \\ tn.academic@gmail.com
}

\section{RESUMO}

A cidade do Recife apresenta uma grande diversidade de construções históricas que possuem diversas manifestações patológicas, que diminuem a vida útil, degradam a estrutura e o patrimônio histórico que é tão valioso. A Igreja Matriz da Boa Vista começou a ser construída em 1784 e só foi concluída em 1889, 105 anos depois, ao estilo arquitetônico renascentista com um frontispício esculpido em pedras Lioz trazidas de Portugal. O edifício foi tombando pelo IPHAN (Instituto do Patrimônio Histórico e Artístico Nacional) em 13 de agosto de 1985. Observou-se que a Igreja vem sofrendo processos de deterioração ao longo dos tempos em suas fachadas, e por esse motivo esse estudo visa diagnosticar o estado de conservação dessa igreja. A inspeção visual e o mapa de danos detalham as manifestações patológicas presentes, entre elas: desagregação, vegetação e grafitti. É possível afirmar que o mapa de danos gera um conteúdo completo e confiável para que se possa indicar uma ação corretiva e eficaz para as manifestações patológicas. Palavras-chave: Manifestações Patológicas, Construção Histórica, Mapa de Danos, Fachada, Igreja.

\begin{abstract}
Recife has a great diversity of historical buildings that have various pathological manifestations, which shorten the useful life, degrade the structure and the historical heritage that is so valuable. The Matriz Church of Boa Vista began its construction in 1784 and was completed in 1889, 105 years later, in Renaissance architectural style with a frontispiece carved from Lioz stones brought from Portugal. The building was federally registration by IPHAN (Institute of National Historical and Artistic Heritage) on August 13, 1985. It has been observed that the church has been undergoing deterioration processes overtime in its facades, and for this reason, this study aims to diagnose the state of conservation of this church. Visual inspection and damage map detail the pathological manifestations present, including breakdown, vegetation and graffiti. It can be stated that the damage map generates complete and reliable content so that corrective and effective action for the pathological manifestations can be indicated.
\end{abstract}

Keywords: Pathological Manifestation, Historic Building, Damage Map, Church, Façade. 


\section{INTRODUÇÃO}

A cidade do Recife é detentora de uma grade herança patrimonial e histórica. Região que ainda antes de ser ocupada como cidade, já desempenhava uma função de grande importância nacional e internacional, tendo sido o porto mais movimentado da América portuguesa por volta do século XVII (ANCORADOURO, 2020). Entretanto, o início de sua ocupação se deu por volta da "terceira década do Século XVI, quando era uma estreita faixa de areia protegida por uma linha de arrecifes que formava um ancoradouro" (IBGE, 2014).

Por volta de 1630, com a ocupação holandesa e com o forte investimento do conde João Maurício de Nassau Siegen, o Recife enfrentou um crescimento urbanístico de grande porte. Essa foi uma "fase que a cidade ganhou palácios, horto zôo-botânico, canais e pontes" (ANCORADOURO, 2020).

Com o decorrer dos anos a cidade continuou a crescer e suas ruas compridas e pátios largos, que dão destaque aos palácios e construções religiosas, foram se multiplicando. Atualmente temos muitos edifícios, sobrados, praças e monumentos que declaram a história da cidade e ostentam a sua riqueza arquitetônica.

As construções religiosas do Recife se destacam entre os muitos edifícios reconhecidos como patrimônio histórico e cultural pelo IPHAN - Instituto do Patrimônio Histórico e Artístico Nacional. Muitas delas têm estado em funcionamento por décadas, e em alguns caso, por mais de séculos, servindo à comunidade católica recifense.

Apesar do grande valor histórico, muitas das edificações tombandas pelo IPHAN não recebem a manutenção necessária para a conservação de sua integridade estrutural e/ou arquitetônica.

Em nossos dias, diante do Recife como a cidade de maior densidade demográfica do estado de Pernambuco e ocupando a nona posição no ranking nacional, com 7.039,64 hab $/ \mathrm{km}^{2}$ (IBGE, 2010), os olhares voltados para a conservação do patrimônio histórico se apresentam em escassez.

Por outro lado, nos dias correntes muitos recursos têm sido desenvolvidos e podem ser utilizados com o propósito de intervir no processo de degradação de edificações históricas, promovendo a sua conservação e a valorização de seu potencial histórico-cultural.

Dessa forma, o objetivo do presente artigo consiste na elaboração de um Mapa de Danos de uma das igrejas mais antigas e singulares da cidade do Recife, a Matriz da Boa Vista, que apresenta características arquitetônicas distinguíveis e um valor histórico motável.

Portanto, por meio de inspeções visuais realizadas em vistorias técnicas, foi construido o mapa de danos da igreja citada, que é uma ferramenta de registro e caracterização das patologias existentes em suas fachadas, com a finalidade de se estudar as possíveis causas dessas patologias, e com isso, facilitar o desenvolvimento de projetos de manutenção e conservação da edificação.

Logo, espera-se contribuir com a conservação do patrimônio histórico da cidade do Recife, promovendo a valorização de sua importância social.

\section{REFERENCIAL TEÓRICO}

De forma generalizada a população entende como patrimônio histórico as construções que tem características arquitetônicas ditas "antigas", o que não está totalmente errado, porém o conceito é um pouco mais amplo. O patrimônio inclui todos os edifícios comuns, jardins e espaços públicos com valor artístico ou arquitetônico que devem ser preservados e que testemunham gostos e correntes artísticas de tempos passados (BEGONHA, 2011).

O patrimônio constitui o testemunho da formação dos povos, afirma Tavares (2011), sendo assim, verifica-se a necessidade de sua preservação para as futuras gerações, proporcionando a manutenção de sua identidade.

A importânica da manutenção e restauração do patrimônio histórico para a conservação da história das sociedades é uma temática levantada desde muito tempo entre os profissionais das ciências humanas e sociais. Durante a reunião da Conferência Geral da Organização das Nações Unidas para Educação, Ciência e Cultura, foi criada a Convenção para a 
proteção do patrimônio mundial, cultural e natural, na qual em seu artigo $1^{\circ}$ define o que é patrimônio cultural, incluindo as obras arquitetônicas como monumentos (UNESCO, 1972).

Ainda antes em 1931, durante o Congresso Internacional de Arquitetos e Técnicos de Monumentos Históricos, em Atenas, foram traçadas diretrizes de como a arquitetura e o urbanismo poderiam atuar na sociedade (CARTA, 1931). Dentre os pontos levanatados estão a administração e legislação dos monumentos históricos.

Com o passar do tempo as mudanças sociais propiciaram o estabelecimento de uma identidade nacional e, consequentemente, o surgimento do sentimento de proteção aos edifícios e ambientes históricos. Entretanto, muitas dessas edificações passam a apresentar diversas manifestações patológicas, que são as anomalias nelas encontradas em decorrência dos muitos anos de uso, muitas vezes sem a devida manutenção. Nesse contexto, intervenções e obras de restauro são as providências recorríveis. Porém, para o início de toda obra de restauração se faz necessário conhecer o objeto que será tratado, para que as técnicas e soluções ideais sejam utilizadas.

O mapa de danos é um documento elaborado com a função de reunir as principais informações sobre o estado de conservação/degradação de um bem histórico. Tinoco (2009) afirma que o mapa de danos consiste em uma "representação gráfico-fotográfica, onde estão ilustradas e discriminadas, rigorosa e minuciosamente, todas as manifestações de deteriorações da edificação, sintetizando o resultado das investigações sobre as alterações estruturas e funcionais nos materiais, nas técnicas, nos sistemas e nos componentes construtivos".

Dessa forma, esse documento permite que iniciativas de projetos de restauração surjam, e assim, o patrimônio analisado seja conservado e sua memória social seja mantida.

\section{METODOLOGIA}

Inicialmente foi realizada uma pesquisa na região escolhida para o estudo, o Bairro da Boa Vista, e dentre as edificações históricas tombadas pelo IPHAN, a Igreja Matriz da Boa Vista foi selecionada como objeto de estudo do presente artigo. Alguns dos critérios avaliados foram a importância social da edificação, a possibilidade de acesso ao prédio e a disponibilidade de material (projetos e inventários) e informações sobre o seu histórico.

Em seguida foi desenvolvido um processo de investigação histórica para caracterização do monumento, que se deu principalmente, por meio de pesquisas bibliográficas e visitas para consultas ao acervo do IPHAN. Além disso, foi feita uma revisão bibliográfica que permitiu a compreensão da importância social e cultural dos monumentos históricos, e a valorização dos propósitos dos projetos de conservação e restauro, que buscam garantir a integridade das edificações históricas.

Para a elaboração do mapa de danos foram necessárias algumas visitas técnicas ao prédio. Por meio dessas visitas foram realizadas vistorias detalhadas, registros fotográficos e croquis das fachadas do templo. As manifestações patológicas foram identificadas e registradas durante as visitas técnicas e analisadas posteriormente em reuniões.

Por fim, as informações levantadas pela análise histórica da edificação, pelas visitas técnicas e com o mapa de danos das fachadas, as manifestações patológicas foram analisadas e suas possíveis causas discutidas.

\section{ESTUDO DE CASO}

\subsection{Delimitação do campo de estudo}

Durante a ocupação (1630-1654), os holandeses trouxeram à cidade cientistas, pintores e engenheiros que contribuíram para que Recife fosse tida como uma das principais cidades da américa no século XVII e XVIII. Nesse período foi realizada a urbanização da cidade, construídas pontes, redes de drenagem, palácios, igrejas e algumas delas estão de pé até os dias de hoje.

Após a expulsão dos holandeses, mesmo com a diminuição do preço do açúcar a cidade continuou a prosperar, fazendo de bairros como a Boa Vista, tivesse grande importância na vida dos recifenses. Sendo considerada por muitos como uma cidade cosmopolita, para a época e com grande importância no comércio de açúcar no panorama mundial, Recife foi e continua sendo palco de manifestações culturais. 
Em nossos dias a Boa Vista possui uma extensão territorial de $1.760 .000 \mathrm{~m}^{2}$, e população residente de 14.778 habitantes, segundo dados do IBGE (2010).

Nesse contexto, através da Lei ${ }^{\circ}$ 18.046/2014, que regulamenta o bairro como a Zona Especial de Preservação do Patrimônio Histórico e Cultural - ZEPH 08, foi instituido um Plano Especial de ocupação para essa região (RECIFE, 2014), em concordância com a Lei Municipal no 17.511/2008 (que promove a revisão do Plano Diretor do município do Recife), com a finalidade de garantir a integridade do patrimônio histórico recifense existente nesse território (RECIFE, 2008).

Logo, pela sua importância histórica, cultural e social o bairro da Boa Vista foi selecionado como campo de estudo para a produção deste artigo.

\subsection{Breve Histórico}

A Igreja surgiu pela necessidade de um templo sede para a Irmandade do Santíssimo Sacramento, que recebeu a confirmação régia de sua fundação legal em 1771, apesar de que as reuniões do grupo já aconteciam a aproximadamente um ano na Igreja da Santa Cruz e apenas em 1778 foi-lhe concedida a sentença para a construção do templo (PIO, 1967).

Em 1784 se deu, de fato início à construção da Matriz, com conclusão das obras principais em 1839. No mesmo ano iniciou-se a importação do atual frontispício. Em 1841 o antigo fronstispício é demolido, sendo o atual apenas concluído em 1889 totalizando em 105 anos de construção (PIO, 1967). Atualmente a Igreja é tombada no âmbito federal pelo IPHAN através do processo $n^{\circ}$ 149-T-38, Livro de Belas Artes, fl. 35, insc. № 199, de 13/08/1985 (IPHAN, 2005).

Em resumo, o frontispício apresentando suporte estrutural, elementos arquitetônicos e elementos decorativos em pedra aparelhada, executada com blocos de Lioz esculpidos, sobrepostos e unidos por argamassa, tendo fechamento interno em alvenaria de tijolos rebocados e revestimento em argamassa com camada de pintura à base de cal branca, acrescenta o autor do inventário.

Dentre outras curiosidades que podem ser destacadas sobre a edificação, o material usado para construção do frontispício é uma delas. A pedra calcária Lioz, ou Pedra Real, foi amplamente utilizada durante a expansão do domínio português de forma a levar a herança portuguesa para cidades importantes da colônia, como Recife, Salvador, Rio de Janeiro e Belém.

\subsection{Características da edificação}

A Igreja Matriz da Boa Vista fica localizada na esquina da Rua da Imperatriz Tereza Cristina com a Rua da Matriz, com a fachada principal voltada para a Imperatriz e Rua do Hospício, ruas de elevado movimento de pessoas graças às atividades comerciais do local.

Em um raio de 500 metros a partir da Igreja (Figura 1), temos construções emblemáticas da cidade do Recife, como a Ponte da Boa Vista, Ponte Duarte Coelho, Cinema São Luiz, Faculdade de Direito do Recife, e outros imóveis tombados, como a Casa de Clarice Lispector e a Casa natal de Manuel Bandeira, caracterizando a localidade com importância cultural entre os cidadãos. 


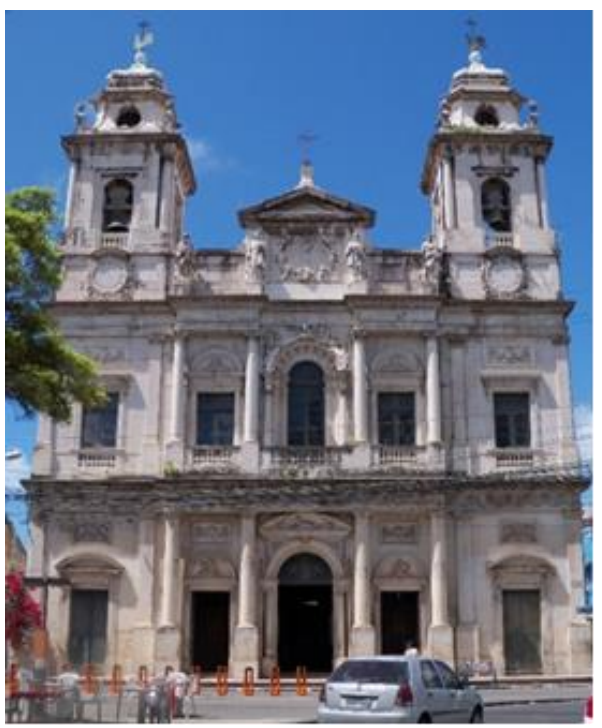

Figura 1: Fotografia da Igreja Matriz da Boa Vista

Para Almeida (2005) um estudo das condições ambientais do meio onde está inserida a obra de cantaria poderá facilitar o reconhecimento da influência dos agentes atmosféricos e ambientais no processo de deterioração da pedra. Para isso, acrescenta, deve-se preliminarmente determinar a variação de temperatura e umidade, o nível de poluição do ar, salinidade do solo, ventos, chuvas, etc.

A proximidade com o Rio Capibaribe e o Oceano Atlântico traz condições bastante definidas da direção e incidência das chuvas sobre a construção (Figura 2).

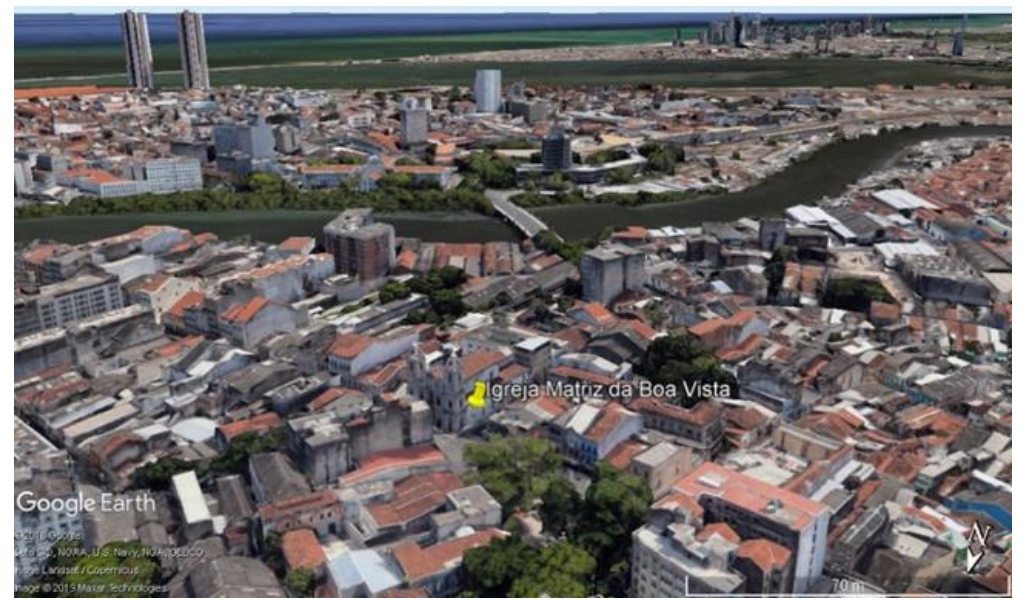

Figura 2: Imagem aérea da localização da Igreja Matriz da Boa Vista

Atualmente a construção conta com uma área de terreno ocupada de aproximadamente $1.400 \mathrm{~m}^{2}$. Possui nos limites de seu terreno um prédio de dois pavimentos (térreo e $1^{\circ}$ andar) utilizado para serviços da comunidade católica e estudos eclesiásticos.

No templo, existem três níveis de pavimentos, sendo o primeiro nível, o térreo, o segundo nível primeiro pavimento e terceiro nível no interior das torres sineiras. As duas torres sineiras possuem cerca de 27 metros de altura e são a parte mais alta da edificação.

Conforme mostrado na a Fachada Leste é voltada para o Oceano Atlântico, e a oposta para Oeste. Sua Fachada Frontal está direcionada para Norte. 


\section{RESULTADOS E DISCUSSÕES}

Durante as vistorias foram identificadas manifestações patológicas provocadas por estresses externos (sobrecarga), estresses internos (cristalização de sais e expanção de material), eventos físicos externos (água da chuva e poluição atmosférica) e ataque biológico (agentes biológicos e vegetação). As principais manifestações patológicas e alterações na edificaçao foram: alteração cromática, alveolização, bolor/limo, corrosão de aço, crosta negra, danos de origem mecânica, depósito, desagregação, desplacamento do reboco, desplacamento do reboco com exposição da alvenaria, destacamento da pintura, detrito, eflorescência, estalado, filme, fissura, fragmentação, intervenção com cimento portland, madeira degradada, manchas, perda, perfuração, pichação, pitting, sujidade, vegetação e vidro danificado.

\subsection{Mapa de Danos}

Após a vistoria, conforme metodologia, foram elaborados os mapas de danos que são o objetivo final desse trabalho. As representações gráficas utilizadas em sua totalidade, em forma de hachura, para identificar as manifestações no desenho estão identificadas na Figura 3.

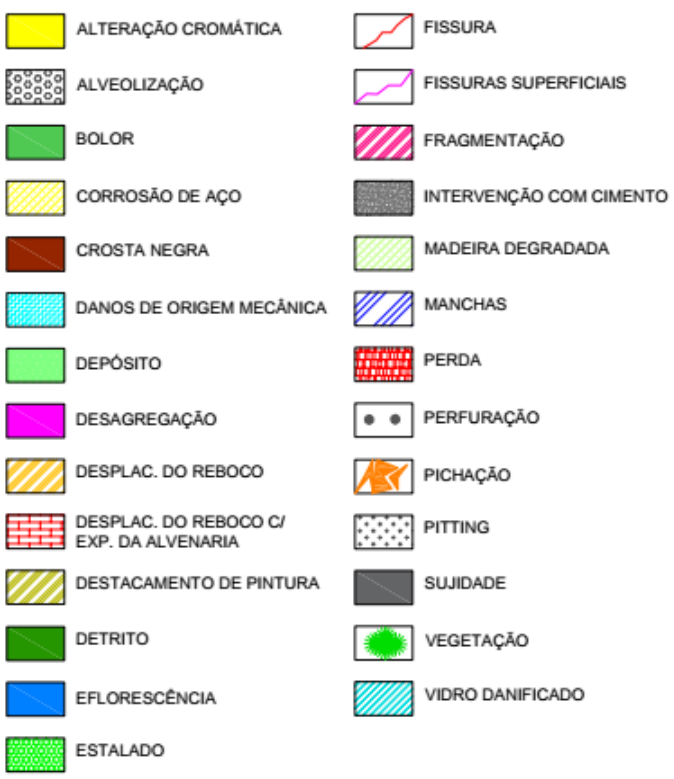

Figura 3: Legenda gráfica utilizada para identificação das manifestações patológicas no Mapa de Danos

Os mapas de danos resultantes das vistorias realizadas na edificação foram tiveram os seguintes resultados:

$\mathrm{Na}$ fachada norte, frontal (Figura 4) visivelmente há maior ocorrência de desagregação e crostas negras. A desagregação acompanha o que já foi abordado, que prova a falta de drenagem das águas pluviais da fachada e falta de manutenção dos elementos. 


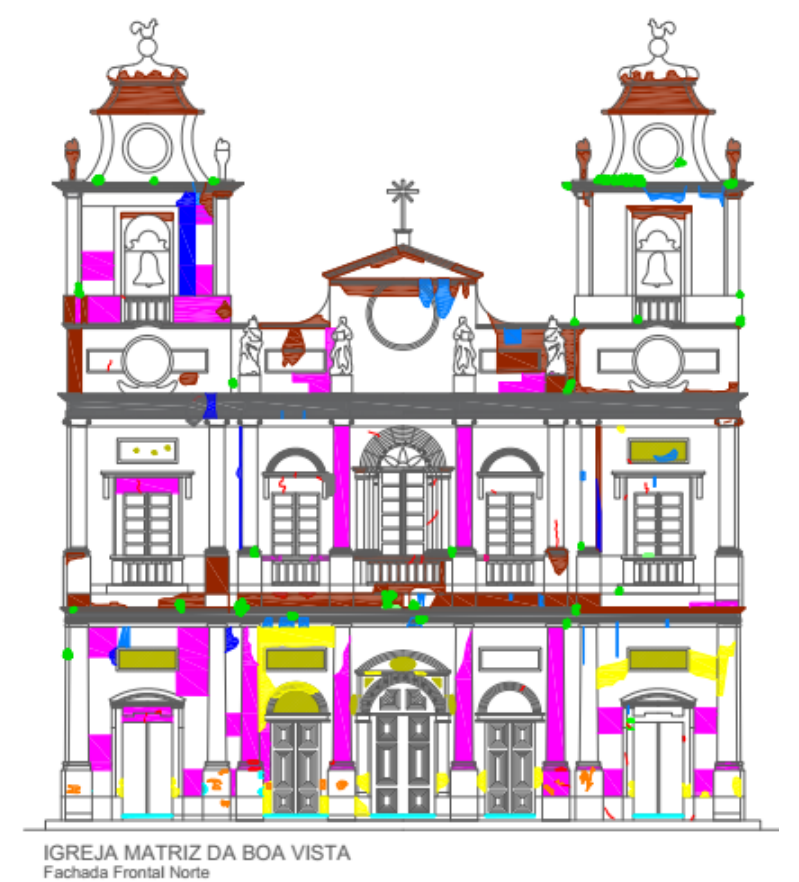

Figura 4: Mapa de Danos da Igreja Matriz da Boa Vista: Fachada Norte

A Fachada Leste (Figura 5), por sua vez, como era de se esperar, foi uma das mais castigadas pelo descuido de drenagem das águas pluviais devido à sua posição em relação aos ventos, sol e mar. Praticamente em toda a sua extensão da parede em alvenaria de tijolos, possui algum tipo de manifestação patológica ligada diretamente à agua. Na região construída em pedra, se manifesta principalmente a desagregação, e na construída em alvenarias prevalecem as manchas, e destacamento de pintura e reboco, inclusive com exposição de alvenaria.

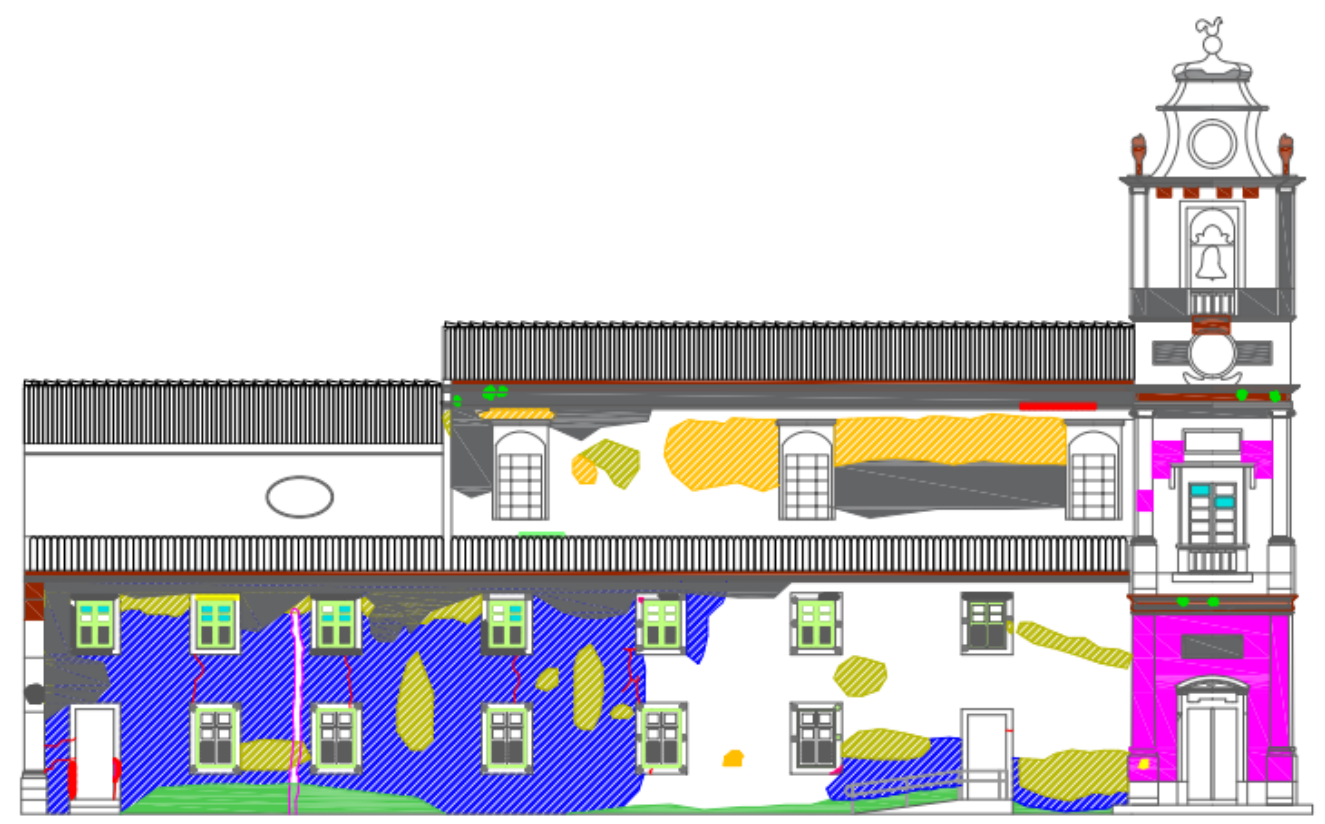

IGREJA MATRIZ DA BOA VISTA

Figura 5: Mapa de Danos da Igreja Matriz da Boa Vista: Fachada Leste

A visível delimitação da região com manchas de umidade evidencia o subdimensionamento da calha de águas pluviais, ou ainda a falta de manutenção das estruturas de cobertura, 
Por fim, a fachada lateral oeste (Figura 6) possui a ocorrência de fissura do tipo verticais que podem caracterizar as seguintes causas: vibração dos veículos que passam na sua imediatamente ao lado da edificação; e/ou deformação do solo que é caracterizado por um aterro de manguezal possuindo solos finos em sua composição. $\mathrm{O}$ bolor/limo na fachada oeste evidencia a falta de impermeabilização do embasamento da fundação.

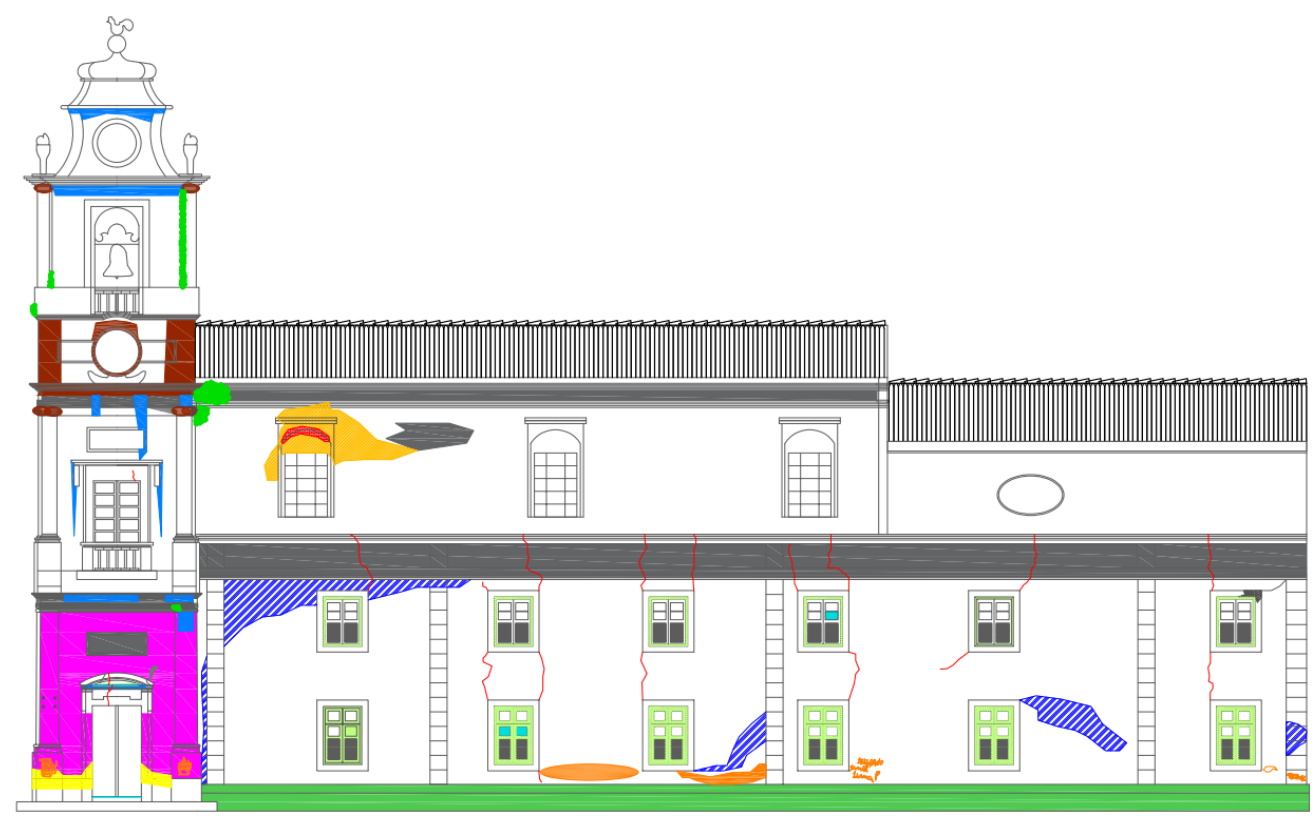

IGREJA MATRIZ DA BOA VISTA

Figura 6: Mapa de Danos da Igreja Matriz da Boa Vista: Fachada Oeste

\subsection{Discussões}

Diante das vistorias e mapas de danos concluídos, temos a possibilidade de quantificar as manifestações patológicas e criticar a ocorrência delas por fachada. A quantificação das manifestações só é possível se separadas em duas frentes de dimensões: as manifestações por região e lineares.

Com os resultados mostrados no gráfico da Figura 7, pode-se constatar que a fachada norte (principal), devido à sua forma e técnica construtiva, apresenta maiores casos de sujidade, crosta negra e desagregação. Como já apontado, por ter regiões protuberantes e recuadas, possibilita a formação das duas primeiras. A desagregação está associada a drenagem da água pluvial e composição da rocha utilizada na cantaria, Pedra Lioz.

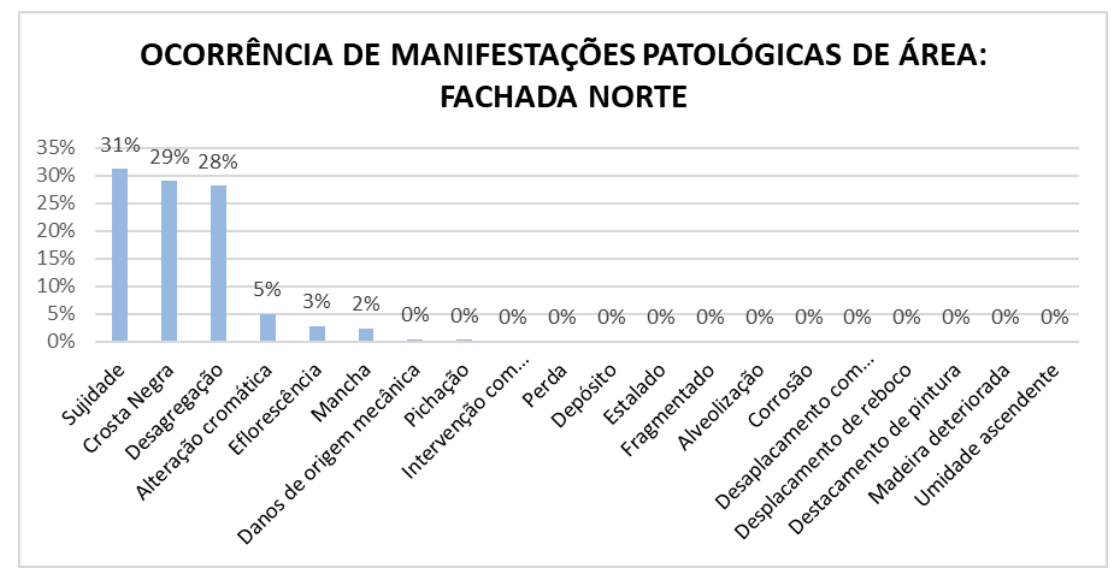

Figura 7: Gráfico de ocorrência de manifestações patológicas de área: Fachada Norte 
A fachada leste (Figura 8), dentre as demais é a que está mais paralela ao mar, tem maior exposição aos ventos e a chuva, fazendo que a ocorrência de manchas seja a principal entre as manifestações por área. A desagregação não tem maior área de abrangência nessa fachada, porém se mostra de forma mais intensa e profunda se comparado com as outras faces da edificação.

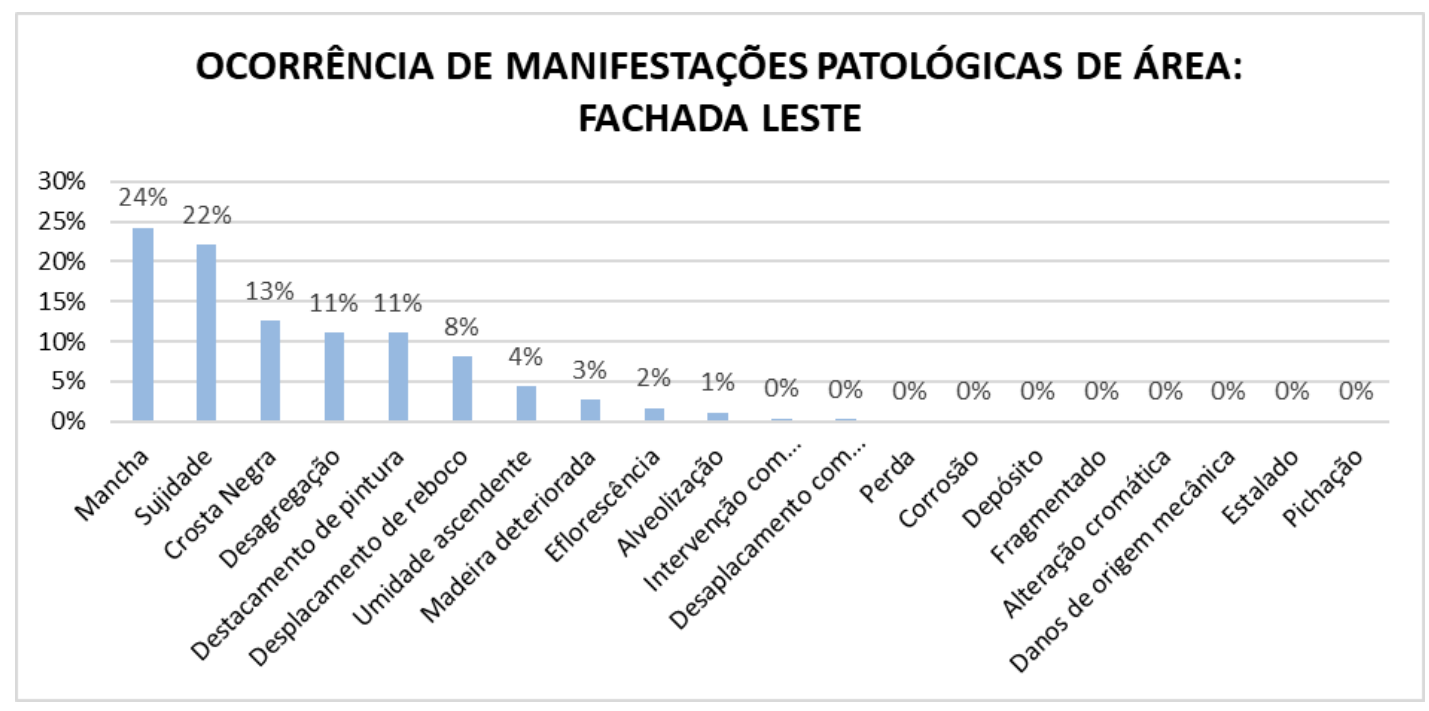

Figura 8: Gráfico de ocorrência de manifestações patológicas de área: Fachada Leste

Na Figura 9, a água e sujeira continuam sendo os principais atores de degradação da estrutura. Por estar mais susceptível há alteração humana, por se localizar numa rua com grande circulação de carros e pessoas é a fachada com mais sinais de vandalismo e manchas.

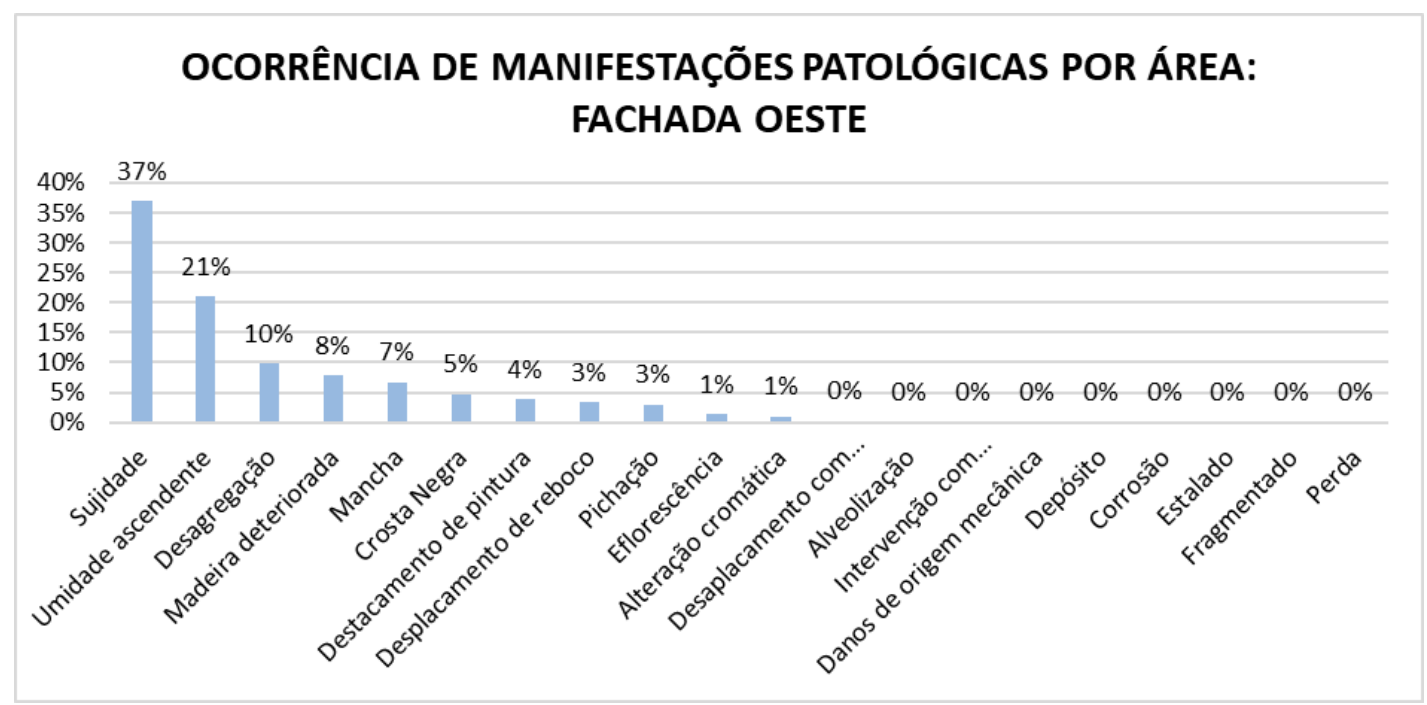

Figura 9: Gráfico de ocorrência de manifestações patológicas de área: Fachada Oeste

As fissuras (Figura 10), manifestações patológicas que foram quantificadas como lineares, como já abordado nos capítulos anteriores, pela sua configuração e localização, a maior parte dela se mostra como sendo o recalque diferencial o maior vilão na fachada oeste. 


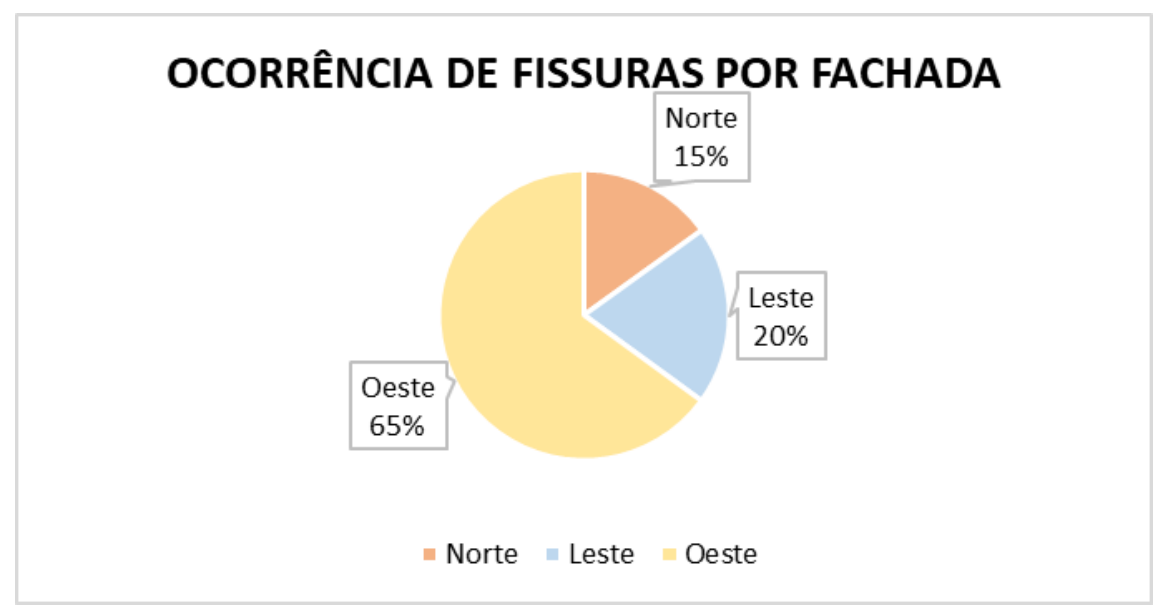

Figura 10: Gráfico de ocorrência de fissuras por fachada

\section{CONCLUSÃO}

O resultado do mapa de danos prova a falta de manutenção externa denunciada por usuários que participam da vida cotidiana na estrutura. As manifestações patológicas identificadas nas fachadas alteram a vida útil da estrutura e influenciam no desempenho e conforto na utilização da edificação (internamente).

Como o escopo desse trabalho está alinhado com o apontamento das manifestações patológicas externas, não coube a inclusão de vistorias técnicas no interior da estrutura, porém como aprimoramento do estudo, seria necessário, além de uma atualização do mapa de danos, o mapeamento das faces internas da estrutura quanto às manifestações patológicas.

Um ponto que deve ser levado em conta é a representação da cantaria que, na sua totalidade, não fica visível com as elevações das fachadas. Devido aos detalhes provenientes do estilo arquitetônico renascentista. A cantaria apresenta reentrâncias e protuberâncias que merecem uma visualização mais detalhada para a equipe restauradora.

Por apresentar um gabarito maior, comparado com as edificações vizinhas, a vistoria fotográfica terrestre é insuficiente para cobrir toda a face externa e superior da estrutura, sendo necessário a instalação de andaimes, ou utilização de drones.

A ocorrência de fissuras precisa ser estudada com mais detalhes. A utilização de ensaios não destrutivos ou destrutivos devem ser avaliados para que o diagnóstico e condutas de correção sejam bem empregados e não danifiquem o patrimônio em questão.

Recomendações para aprimoramento do estudo:

- Vistoriar visualmente todas as fachadas com auxílio de drone;

- Realizar ensaios destrutivos ou não para melhor compreensão da estrutura;

- Verificar as fundações para diagnóstico sobre as fissuras;

- Sugerir formas de conduta para solucionar as manifestações encontradas.

\section{AGRADECIMENTOS}

À Prof ${ }^{a}$ Eliana Monteiro por me acolher no grupo de pesquisa que tem um impacto fundamental na cidade do Recife, à Prof $^{a}$ Lydia Marques pela orientação durante o estudo, e, principalmente aos amigos Moura Júnior e Thulio Nascimento pela força e grande ajuda que desde o início incentivaram a realizar esta publicação. 


\section{REFERÊNCIAS}

ALMEIDA, F. N. F. Manual de conservação de cantarias. Instituto do patrimônio histórico artístico e nacional IPHAN: 2005. 43p.

ANCORADOURO. Ancoradouro de navios e ideias. Disponível em: <http://www2.recife.pe.gov.br/pagina/hisoria> Acesso em: 17 fev. 2020.

BEGONHA, A; Patologia da pedra. Casos de obra. In: JORNADAS DE MATERIAIS DE CONSTRUÇÃO. Porto, Portugal: 2011.

ESCRITÓRIO INTERNACIONAL DOS MUSEUS SOCIEDADES DAS NAÇÕES. Carta de Atenas, 1931. Disponível em: < http://portal.iphan.gov.br/uploads/ckfinder/arquivos/Carta\%20de\%20Atenas\%201931.pdf>

INSTITUTO BRASILEIRO DE GEOGRAFIA E ESTATÍSTICA - IBGE. Recife, 2010. Disponível em: <https://cidades.ibge.gov.br/brasil/pe/recife/panorama>. Acesso em: 17 fev. 2020.

INTERNACIONAL SCIENTIFIC COMMITTEE FOR STONE. Glossário ilustrado das formas de deterioração da pedra. ICOMOS: 2008 .

IPHAN. Inventário Nacional de Bens Móveis e Integrados: Igreja da Boa Vista (Igreja do Santíssimo Sacramento Matriz da Boa Vista), Recife - Pe, 2005.

MESQUITA, E.; PAUPÉRIO, E.; ARÊDE, A.; VARUM, H. Boletim Técnico no 11: Caracterização, avaliação e recuperação estrutural de construções históricas. ASOCIACIÓN LATINO AMERICANA DE CONTROL DE CALIDAD, PATOLOGIA Y RECUPERACIÓN DE LA CONSTRUCCIÓN - ALCONPAT INT. México, 2015.

PIO, F. História da Matriz da Boa Vista e seu Monumental Frontispício. Recife, 1967.

RECIFE (Município). Lei $\mathbf{n}^{\mathbf{0}}$ 17.511, de 29 de dezembro de 2008. Promove a Revisão do Plano Diretor do Município do Recife. Recife, PE, Disponível em: 〈https://leismunicipais.com.br/plano-diretor-recife-pe〉. Acesso em: 18 fev. 2020.

RECIFE (Município). Lei $\mathbf{n}^{\circ}$ 18.046, de 25 de julho de 2014. Regulamenta a Zona Especial de Preservação do Patrimônio Histórico e Cultural - ZEPH 08 - Boa Vista, Instituindo o Plano Específico para os Setores de Preservação Ambiental (SPA), de acordo com o estabelecido nos Artigos 103, II, 115, 117 C/C 147, I "I", 193, XII, e 194, da Lei Municipal $\mathbf{n}^{\mathbf{0}}$ 17.511/2008, e dá outras providências. Recife, PE, Disponível em: $<$ https://leismunicipais.com.br/a/pe/r/recife/lei-ordinaria/2014/1804/18046/lei-ordinaria-n-18046-2014-regulamenta-azona-especial-de-preservacao-do-patrimonio-historico-e-cultural-zeph-08-boa-vista-instituindo-o-plano-especifico-paraos-setores-de-preservacao-ambiental-spa-de-acordo-com-o-estabelecido-nos-artigos-103-ii-115-117-c-c-147-i-i-193-xiie-194-da-lei-municipal-n-17511-2008-e-da-outras-providencias>. Acesso em: 18 fev. 2020.

TAVARES, F. M. Metodologia de diagnóstico para restauração de edifícios dos séculos XVIII e XIX nas primeiras zonas de mineração em Minas Gerais. Juiz de Fora, 2011. Dissertação de mestrado em ambiente construído, Universidade Federal de Juiz de Fora.

TINOCO, J. E. L. Mapa de danos, recomendações básicas. Centro de estudos avançados da conservação integrada. Olinda, 2009.

UNESCO. Convenção para a proteção do patrimônio mundial, cultural e natural. Paris, 1972.

Ficha de identificação de danos - FID, na modelagem de um mapa de danos. Centro de estudos avançados da conservação integrada. Olinda, 2019. 